Nationalism, Cognitive Ability, and Interpersonal Relations

Giacomo Corneo

School of Business \& Economics

Discussion Paper

Economics

$2010 / 5$

978-3-941240-17-9 


\title{
Nationalism, Cognitive Ability, and Interpersonal Relations
}

\author{
Giacomo Corneo* \\ March, 2010
}

${ }^{*}$ This article builds on a keynote lecture that I delivered at the conference "Happiness and relational goods: Well-being and interpersonal relations in the economic sphere" in Venice, June 12, 2009. I thank an anonymous referee and Benedetto Gui for detailed comments as well as Holger Lüthen and Frank Neher for excellent research assistance.

Affiliation of author: Department of Economics, Free University of Berlin; CEPR, London; CESifo, Munich; IZA, Bonn.

Address of author: Department of Economics, FU Berlin, Boltzmannstr. 20, 14195 Berlin, Germany. Email: giacomo.corneo@.fu-berlin.de. 


\begin{abstract}
Interpersonal relations are shaped by the judgements associated with the social categories that individuals perceive in their social contacts. I develop a model of how those judgments form based on a theory of symbolic values. The model depicts the interaction between two values, one associated with an inherited ethnic trait ("nationality") and one with an endogenous achievement trait ("income"). Individuals with lower cognitive ability are predicted to invest more value on nationalism and to have hostile relations with immigrants. Multiple equilibria are possible and better schooling may eliminate equilibria with xenophobia. Econometric findings based on data from three large surveys corroborate the predictions derived from the theoretical model.
\end{abstract}

Keywords: nationalism, xenophobia, interpersonal relations, value systems.

JEL-Classification: Z1. 


\section{Introduction}

Interpersonal relations have an idiosyncratic and a common component. On the one hand, any interpersonal relation is the product of a unique history of interactions between concrete human beings and of their memories of that history. On the other hand, interpersonal relations unfold in a socially constructed mental frame: individuals encounter each other as carriers of traits whose saliency and meaning are to a large extent socially determined. People first meet as men and women, white and black, subordinate and boss, and only after - if their communication deepens - as individualized persons. First encounters ${ }^{1}$ are governed by the expectations and judgements associated with the social categories - like gender, race, and occupation - that individuals perceive in their social contacts. Those judgements heavily affect the utility derived from interpersonal relations. They may determine whether a first encounter begins with a smile or with raised eyebrows, with deference or disdain, with a handshake or an erected finger. And the quality of a first encounter may determine whether the relation continues and on which track. Since social judgments carry such heavy consequences, people's search for personal contacts as well as their efforts to avoid them, along with the resulting network of relations, depend on the prevailing stereotypes associated with social categories.

This paper considers the case where people's evaluation of social categories are a matter of choice. Based on a theory of symbolic values proposed by Corneo and Jeanne (2009, 2010), I explore the extent to which parents interested in their children's welfare will teach them to believe in the superiority of their own nation and to despise immigrants. The model offers an explanation for the emergence of xenophobia without positing adverse economic effects of immigration for natives. Thus, it conforms well with recent empirical findings by Card et al. (2009) on the determinants of attitudes towards immigration in Europe. They find that "compositional amenities" - associated with the non-economic consequences of immigration - are substantially more important in explaining attitudes than concerns over the impacts of immigration on wages and taxes. Those amenity effects are found to be especially strong in case of less-educated natives.

The model in this paper captures the idea that parents try to transmit values that serve best their children's interest both in terms of their economic welfare and self-esteem. By stressing the importance of economic success, parents make their children more willing to exert work effort and increase the probabililty that they will eventually reach a high income

\footnotetext{
${ }^{1}$ Gui (2005) introduced this terminology to describe those peculiar acts of production and consumption that characterize interpersonal relations from an economic viewpoint.
} 
level. However, economic success is uncertain and stressing economic success carries the risk of a loss of self-esteem in case of bad luck. Teaching pride in own nation is an easy way to sustain one's self-esteem without risk. When parents choose how much value they put on economic success and national pride, they compare the benefits that those values confer upon their children with the costs of instilling values. That trade-off turns out to hinge upon the ability of children - because higher ability increases the probability to have a high income. The model predicts that above a certain threshold, nationalism is decreasing with individual ability. Parents of high-ability children expect them to be successful with high probability; for them it is optimal to strenghten the achievement orientation of their children thereby increasing further the probability of success and at the same time raising the probability of a high level of self-esteem. Since a heavier investment in achievement orientation increases the marginal cost of further socializing their children, parents of high-ability children optimally decrease their investment in national pride. Conversely, parents of low-ability children anticipate a low probability of economic success and prefer to instill nationalism so as to secure at least some self-esteem to their children. Analysis of this trade-off for very low levels of ability reveals that the opposite pattern - where nationalistic attitudes are increasing with ability - can also exist. In the general case, the relationship between nationalism and ability is therefore hump-shaped.

This paper proceeds as follows. In Sect. 2, I sketch the main ideas of the theory of symbolic values developed by Corneo and Jeanne (2009 and 2010). Sect. 3 applies that theory to nationalism, studies the relations between natives and immigrants, and shows the causal effect of ability on nationalism. In Sect. 4, the model's prediction are confronted with empirical evidence obtained from three large representative surveys. Sect. 5 concludes.

\section{Theory of symbolic values}

Some personal characteristics, like nationality and level of income, seem to be invested with symbolic values by human beings. These values determine the esteem that individuals receive from other people as well as their self-esteem. Those values are symbolic in the sense that they are intangible: they affect the well-being of individuals - so they are values - but without affecting their consumption of material goods - so they are symbolic. A system of symbolic values is a set of judgments about salient characteristics. A theory of symbolic values should explain the variation of those judgments across social groups and single individuals. The theory of symbolic values developed in Corneo and Jeanne $(2009,2010)$ is based on four main assumptions: 
1) Evaluative attitude. Individuals pass judgments of approval, admiration, etc., and their opposite upon certain traits, acts, and outcomes.

Those judgements are determined by an individual's value system, which is a way to allocate value to bundles of judgeable characteristics. Formally, the value system of an individual is a function that maps an exogenous set of judgeable types onto the real line.

2) Social approbativeness. Individuals desire a good opinion of oneself on the part of other people.

The relevant human environment for approbativeness may be an individual's family, friends, colleagues, neighbors, or society at large. The desired ways of thinking may be in a scale that distinguishes contempt, indifference, interest, approval, praise, admiration, and veneration.

3) Self-approbativeness. Individuals have a desire for self-esteem.

The desire for a pleasing idea of oneself presupposes self-consciousness. Humans are both actors and spectators of what they do. Since they are evaluative beings, they also judge themselves.

4) Consistency. The standards of approbation or disapprobation which the individual applies to himself are the same as those which he applies to other people.

This postulate corresponds to the rule of judging yourself as you would judge of others. While psychologists have identified ways of self-deception, in the main individuals are subject to the control by the logic of consistency. It is difficult to systematically approve in oneself acts which one condemns in others, and when one does so, his fellows are quick to point out the inconsistency.

Value systems arise within various socialization structures. Symbolic values are transmitted in a cultural process by agencies of socialization like the family, the peers, and the media. Parents are a main agency of socialization and the models in Corneo and Jeanne $(2009,2010)$ employ the theory of symbolic values to study how altruistic parents socialize their children in various contexts that matter for economic growth and respect for diversity.

The idea that values are not fixed but purposively chosen led Akerlof (1983) to develop models of the labor market where parents teach their children to be loyal to employers. Akerlof and Kranton (2000)'s economic theory of identity further generalized that approach. Bisin and Verdier $(1998,2000)$ combined purposive socialization with an evolutionary approach. In their models, vertical socialization, along with random imitation, determines the long-term distribution of cultural traits in the population. A comparison of those approaches with the theory of symbolic values sketched above is offered in Corneo and Jeanne (2009). 


\section{A model of immigrants-natives relations}

Beliefs in the superiority of one's own ethnicity can have serious implications for the relations between immigrants and natives and for a country's economic performance. Immigrants constitute a sizeable share of the overall world population and often belong to the most vulnerable strata of the population. Negative stereotypes about immigrants reduce their chances in the labor market and their quality of everyday life, including life at schools and in workplaces. Natives' hostility may foster negative stereotyping by immigrants with respect to the national majority, giving rise to a mental arm race in terms of prejudices. That arm race can affect political outcomes and even turn into episodes of violence. $^{2}$ From an economic viewpoint, chauvinistic attitudes may be a formidable obstacle to the immigrants' integration in the domestic economy and the recognition of their talents. Natives' hostility may induce immigrants to cluster together in neighborhoods and schools, where unfavorable peer effects prevent both cognitive and noncognitive abilities to develop as they could. In this fashion, xenophobia may generate a lasting negative impact on innovation and economic growth.

In the sequel, a formal model of immigrant-natives relations is developed that allows one to dissect the role of value formation and the interplay between symbolic values and economic outcomes. ${ }^{3}$

\subsection{Assumptions}

Consider a model economy populated by a continuum of atomistic individuals $i \in[0,1]$. Individuals have a common utility function but differ with respect to their nationality, ability, and family background. A fraction $\mu$ of the population consists of immigrants, a fraction $1-\mu$ consists of natives; for simplicity, all immigrants are assumed to share a common nationality. Ability refers to cognitive skills, as opposed to noncognitive skills

\footnotetext{
${ }^{2}$ In Germany, right-wing extremist parties could benefit from mounting xenophobia and anti-Semitism in some recent regional elections; as reported by Siedler (2008), between 1990 and 2005 the number of right-wing extremists in Germany more than doubled. Anti-immigrant feeling was a key factor in the electoral success of the National Front Party in the 2002 French election; as simulated by Roemer and Van der Straeten (2005), xenophobia substantially reduced the redistributive content of the parties' electoral platforms. Historically, feelings of superiority of own nation have helped to legitimize fascism, colonialism and imperialism. In turn, fascist leaders used their rethoric to foster racial and ethnic divisions.

${ }^{3}$ Bisin et al. (2008) and Della Giusta and Hashimzade (2009) offer related models of cultural assimilation of immigrants. The model in the current paper can also be interpreted as one of racial relations. I do not touch on the important issue of how values affect the extent of racial and ethnic discrimination in labor markets. See on this the recent contribution by Vendrik and Schwieren (2010). Notice that statistical discrimination seems to leave a considerable part of observed discrimination unexplained. In controlled experiments, Fershtman and Gneezy (2001) found no evidence of statistical discrimination and much evidence in support of mistaken ethnic stereotypes.
} 
that in the current model are mirrored by the endogenous values endorsed by the individuals. ${ }^{4}$ Cognitive ability is summarized by the pair $(\pi, \theta)$ and family background by the pair $(\alpha, \eta)$, to be explained later. No restriction on the joint distribution of the ability and family-background paramters in the population is imposed. All individuals consume one homogeneous good, used as the numeraire. Each individual faces the following sequence of events: first, the individual exerts effort in order to shape his value system; this can be interpreted as a benevolent parent socializing her child. Second, the individual, given his values, decides how much effort to exert in order to achieve in economic terms. Third, Nature determines the individual achievement levels; individuals consume according to their achievements and obtain esteem and utility from interpersonal relations according to how their characteristics are valued in society.

\section{Material Outcomes}

Achievement is defined in terms of the income level received by the individual when adult, which can be either the high income level $w_{H}$ or the low income level $w_{L}$. Achieving is a random event which depends on an individual's ability and his effort during adulthood. Ability is determined by exogenous factors, like inherited family traits and the quality of compulsory schooling received by the child. Denoting by $e(i)$ individual $i$ 's non-negative effort level, the probability to succeed is given by $\operatorname{Pr}\left\{w(i)=w_{H}\right\}=\pi(i)+\theta(i) e(i)$, where parameters $\pi$ and $\theta$ are both non-negative. Parameter $\pi$ stands for those individual capabilities that increase achievement independently of an individual's effort; $\theta$ measures the extent to which individual achievement is responsive to individual effort. Effort is costly, and its cost to the individual is specialized to $e(i)^{2} / 2 \omega$, where $\omega$ is a preference parameter of the utility function.

Let $\lambda$ denote the fraction of achievers. Their wage $w_{H}(\lambda)$ is assumed to satisfy $w_{H}^{\prime}(\lambda) \leq$ 0 , while $w_{L}^{\prime}(\lambda) \geq 0$, with $w_{H}(1)>w_{L}(0)$. The first two inequalities can be seen as a reduced-form model for a labor market determination of the returns to human capital.

Value systems.

Individuals have value systems defined over two attributes: nationality $n \in\{0,1\}$ and achievement $a \in\{0,1\}$. Let $n=1$ denote domestic nationality and $a=1$ denote high income. The value attached to the trait combination an by individual $i$ is measured by a non-negative index $v_{a n}(i)$. The collection of the four $v_{a n}(i)$, one for each type, describes the value system of individual $i$; it satisfies

\footnotetext{
${ }^{4}$ As shown by empirical research on human development, cognitive ability as measured by IQ scores becomes stable much earlier in life than noncognitive ability. This is asociated with the slowly developing prefrontal cortex, see e.g. Cunha and Hekman (2009).
} 


$$
\sum_{a=0}^{1} \sum_{n=0}^{1} v_{a n}(i)=1
$$

Value systems are determined by an exogenous factor that is common to all individuals with the same nationality (possibly the same for both nationalities) and by an endogenous idiosyncratic factor. The common factor is the reference value system $\left\{\widehat{v}_{a n}\right\}$ for nationals and $\left\{\widetilde{v}_{a n}\right\}$ for immigrants. The reference value system mirrors public values as put forward by collective discourse. They are the outcome of a whole history of ideas and taken as exogenously given. By way of an example, public values that stress the fundamentally equal worth of all individuals, independently of their traits, may be captured by $\widehat{v}_{a n}=1 / 4$ for all $a$ and $n$. Public values that stress the superiority of own country of origin may instead give rise to $\widehat{v}_{a 1}>\widehat{v}_{a 0}$ and $\widetilde{v}_{a 0}>\widetilde{v}_{a 1}$; public values that stress the special worth of individual accomplishments may induce $\widehat{v}_{1 n}>\widehat{v}_{0 n}$ and $\widetilde{v}_{1 n}>\widetilde{v}_{0 n}$.

The idiosyncratic factor captures how an individual is socialized. I concentrate on vertical socialization by benevolent parents, thus abstracting from horizontal and oblique socialization. If parents do not exert effort, individuals are assumed to endorse the reference value system of their nationality. By exerting efforts, parents can shift their child's values away from the reference value system. This captures the malleability of character during childhood and early adolescence that has been identified by research on human development. ${ }^{5}$

Parents who invest in their children's values may influence the relative value that their children attach to achievement, which is given by $\sum_{n=0}^{1} v_{1 n}(i)-\sum_{n=0}^{1} v_{0 n}(i)$. At the same time, they may influence the relative value that their children attach to nationality, $\sum_{a=0}^{1} v_{a 1}(i)-\sum_{a=0}^{1} v_{a 0}(i)$. Parents' influence depends on the amount of resources that they use to socialize their children. Let $\left|\delta_{a}(i)\right|$ and $\left|\delta_{n}(i)\right|$ respectively denote a parent's investment in achievement orientation and in nationalism; a positive $\delta_{a}(i)$ stands for putting more emphasis on achievement orientation as compared to the reference value system; a positive $\delta_{n}(i)$ stands for increased nationalism if $i$ is a native family and for decreased nationalism if $i$ is an immigrated family. The resulting value system for a native is given by:

$$
\begin{aligned}
& v_{11}(i)=\max \left\{\min \left\{\widehat{v}_{11}+\delta_{a}(i)+\delta_{n}(i), 1\right\}, 0\right\} \\
& v_{01}(i)=\max \left\{\min \left\{\widehat{v}_{01}-\delta_{a}(i)+\delta_{n}(i), 1\right\}, 0\right\}
\end{aligned}
$$

\footnotetext{
${ }^{5}$ See e.g. Cunha and Heckman (2009).
} 


$$
\begin{gathered}
v_{10}(i)=\max \left\{\min \left\{\widehat{v}_{10}+\delta_{a}(i)-\delta_{n}(i), 1\right\}, 0\right\} \\
v_{00}(i)=\max \left\{\min \left\{\widehat{v}_{00}-\delta_{a}(i)-\delta_{n}(i), 1\right\}, 0\right\} .
\end{gathered}
$$

Analogous expressions hold for immigrants after substituting $\widehat{v}_{a n}$ with the corresponding $\widetilde{v}_{a n}$. Without significant loss of generality, I assume that parameters are such that parents choose internal values, i.e. $v_{a n}(i) \in(0,1)$ for all $a, n$ and $i$.

Instilling individual values is assumed to be costly for parents, e.g. because they have to spend time teaching them or because they have to buy services from distinctive educational institutions. Specifically, there is firstly a cost caused by the overall amount of socialization effort exerted by parents, $\left|\delta_{a}(i)\right|+\left|\delta_{n}(i)\right|$. Secondly, parents incur a specific cost for manipulating the value attached to each single trait, achievement and nationality. Both costs can be thought of as depending on a parent's skill in transmitting values. Parents whose own value system attaches a large value to achievement must spend less effort in order to obtain a given increase in her children's valuation of achievement as compared to parents who attach little value to achievement. Similarly, nationalistic parents have a comparative advantage in transmitting an attachment to nation. Total costs incurred by an individual's parent to socialize her child are specialized to

$$
\frac{\left(\left|\delta_{a}(i)\right|+\left|\delta_{n}(i)\right|\right)^{2}}{2 \sigma}+\frac{\delta_{a}(i)^{2}}{2 \alpha}+\frac{\delta_{n}(i)^{2}}{2 \eta} .
$$

Parameters $\alpha$ and $\eta$ capture both the values of the parents and the intrinsic strength of the national value system: the weaker parents' valuation of a given trait and the more convincing the reference value system of their group, the larger are the costs to inculcate different values, and the smaller are $\alpha$ and $\eta$.

\section{Utility function.}

Families care about consumption, self-esteem and interpersonal relations, in addition to effort costs. Their additively separable preferences are represented by the utility function

$$
U(i)=c(i)+\beta \operatorname{self} v(i)+\gamma \operatorname{socv}(i)-\left[\frac{\left(\left|\delta_{a}(i)\right|+\left|\delta_{n}(i)\right|\right)^{2}}{2 \sigma}+\frac{\delta_{a}(i)^{2}}{2 \alpha}+\frac{\delta_{n}(i)^{2}}{2 \eta}+\frac{e(i)^{2}}{2 \omega}\right] .
$$

The first term on the r.h.s. captures the child's utility from consumption, which is given by his wage when adult. The second one captures utility from self-esteem. An individual's self-esteem is the esteem in which he holds his type: an individual $i$ of type an has self-esteem $v_{a n}(i)$. Self-esteem has a value per se, independently of social interactions. The utility derived from those interactions is captured by the third term of the utility 
function. I assume that adult individuals are randomly matched into pairs. At each encounter they exchange courtesy or hostility according to their traits and values. Courtesy and hostility are relational goods that are not exchanged through markets but through social interactions. For brevity, I refer to the entire set of goods consumed within those interpersonal relations as to the social esteem experienced by individuals. The treatment that an individual receives from a social contact depends on the value attached by his social contact to the individual's type. I assume that nationality is perfectly observed by social contacts, while achievement is observed with probability $1-\rho$. The expected social esteem received by a native with achievement level $a \in\{0,1\}$ is therefore given by

$$
\operatorname{socv}(i)=(1-\rho) \int_{0}^{1} v_{a 1}(j) d j+\rho\left[\widehat{a} \int_{0}^{1} v_{11}(j) d j+(1-\widehat{a}) \int_{0}^{1} v_{01}(j) d j\right],
$$

where $\widehat{a}$ is the fraction of achievers in the native population. A symmetric definition of socv $(i)$ applies for migrants. ${ }^{6}$

The preference parameters $\beta$ and $\gamma$ are strictly positive; they respectively capture the strength of the concern for self-esteem and for the quality of interpersonal relations.

Equilibrium.

An equilibrium is a situation in which each family (i.e. parent-child couple) chooses its effort levels to shape its values and to obtain high income so as to maximize its expected utility, taking the choices of all other families as given. To shorten the exposition, I only consider parameter constellations that give rise to equilibria that are interior with respect to the probability to achieve, i.e. such that $\pi+\theta e \in(0,1)$.

\subsection{Individual optimization}

At the family level, both the wage structure and the allocation of social esteem are taken as exogenouos. A native family maximizes

$$
(\pi+\theta e)\left[w_{H}+\beta\left(\widehat{v}_{11}+\delta_{a}+\delta_{n}\right)+\gamma \operatorname{socv}_{11}\right]+(1-\pi-\theta e)\left[w_{L}+\beta\left(\widehat{v}_{01}-\delta_{a}+\delta_{n}\right)+\gamma \operatorname{socv} v_{01}\right]-C\left(\delta_{a}, \delta_{n}, e\right),
$$

where

$$
C\left(\delta_{a}, \delta_{n}, e\right)=\frac{\left(\left|\delta_{a}\right|+\left|\delta_{n}\right|\right)^{2}}{2 \sigma}+\frac{\delta_{a}{ }^{2}}{2 \alpha}+\frac{\delta_{n}{ }^{2}}{2 \eta}+\frac{e^{2}}{2 \omega}
$$

\footnotetext{
${ }^{6}$ This modeling of social interactions could be enriched along several dimensions. First, individuals may be assumed to care more about the esteem received from somebody of the same nationality. Second, individuals may be assumed to have a higher probability to meet somebody of the same nationality. These two extensions would have similar implications. Finally, the matching rate could be endogenized, as e.g. in Corneo (2005).
} 
is a shorthand for the costs incurred by the agent as a function of his three control variables. The immigrants' decision problem is similar and will not be explicitly presented.

As a first step, it is instructive to discuss the determination of the child's achievement level. When the child selects his effort, his value system has already crystallized, inducing reduced-form preferences for effort summarized by the objective function

$$
(\pi+\theta e)\left(w_{H}+\beta v_{11}+\gamma s o c v_{11}\right)+(1-\pi-\theta e)\left(w_{L}+\beta v_{01}+\gamma s o c v_{01}\right)-\frac{e^{2}}{2 \omega} .
$$

The first-order condition for an interior maximum entails

$$
e^{*}=\omega \theta\left[\left(w_{H}-w_{L}\right)+\beta\left(v_{11}-v_{01}\right)+\gamma\left(\operatorname{socv}_{11}-\operatorname{socv}_{01}\right)\right] .
$$

Thus, an individual's expected achievement $\pi+\theta e^{*}$ is driven by four factors: his ability, as proxied by $\pi$ and $\theta$, his character, as proxied by $v_{11}-v_{01}$, pecuniary incentives, $w_{H}-w_{L}$, and social incentives, $\operatorname{socv}_{11}-\operatorname{socv}_{01}$. As shown by (6), values transmitted to the individual by society and his parents generate an incentive effect: the individual's effort is strictly increasing with $v_{11}-v_{01}=\widehat{v}_{11}-\widehat{v}_{01}+2 \delta_{a}$. The intuition is simple: the larger the value attached to achievement, the larger is the self-esteem obtained from achieving relative to the self-esteem in case of failure, and the stronger is the incentive for the individual to exert effort. ${ }^{7}$

When parents socialize their children, they anticipate the incentive effect of value transmission. The result of their maximization exercise is described in the following ${ }^{8}$

Proposition 1 A unique optimal strategy always exists and has $\delta_{n}^{*}>0$ in case of natives and $\delta_{n}^{*}<0$ in case of immigrants. Depending on parameter values, one of the following cases occur at the optimum: 1) $\delta_{a}^{*}<0, e^{*}=0$;2) $\delta_{a}^{*}<0, e^{*}>0$; 3) $\delta_{a}^{*}=0, e^{*}>0$; 4) $\delta_{a}^{*}>0, e^{*}>0$.

Parents have an incentive to invest in nationalism because it has a positive influence on the child's self-esteem for sure and a small investment causes negligible costs. Instead, parents do not necessarily invest in the achievement-orientation of their children. The

\footnotetext{
${ }^{7}$ This result accords well with empirical findings from wage regressions reported by Fortin (2008). Using US longitudinal survey data, she shows that attaching value to economic success when the individual is in his teens significantly raises the individual's wage when he is age 32 .

${ }^{8}$ Proofs of all propositions appear in the Appendix. In order for the maximization problems to be well-behaved, parameters must satisfy

$$
\alpha+\eta+\sigma>4 \alpha \beta^{2} \theta^{2} \omega(\eta+\sigma),
$$
}

which I assume to be the case throught the paper. 
welfare impact of investing in achievement orientation can be decomposed into a direct and an indirect effect. The direct effect is the expected change in self-esteem caused by attaching more value to achievement. Its expected return is positive if and only if the

probability for the child to be an achiever (given by $\pi+\theta e$ ) is larger than the probability to be a loser (given by $1-\pi-\theta e$ ). The indirect effect stems from the change in the marginal return to effort. Increasing the achievement-orientation of the child generates an incentive to exert more effort because the achievement orientation increases the loss of self-esteem in case of failure. If the probability to achieve is low, the direct effect dominates and the parent decides to invest to decrease the achievement orientation of her child $\left(\delta_{a}^{*}<0\right)$. If the probability is high, the direct and the indirect effects reinforce each other and the parent chooses to enhance the achievement orientation of her child $\left(\delta_{a}^{*}>0\right)$.

\subsection{General equilibrium}

At the general-equilibrium level, the income levels of achievers and losers and the social esteem of each type are endogenous. The wage determination follows the usual logic of scarcity: the wage differential is given by

$$
\Delta w=w_{H}((1-\mu) \widehat{a}+\mu \widetilde{a})-w_{L}((1-\mu) \widehat{a}+\mu \widetilde{a}),
$$

which is decreasing in the fraction of achievers in the two groups, $\widehat{a}$ and $\widetilde{a}$.

The difference in social esteem between achievers and losers reads

$$
\Delta \widehat{\text { SOCV }}=(1-\rho)\left[(1-\mu)\left(\widehat{v}_{11}-\widehat{v}_{01}+2 \widehat{\delta}_{a}\right)+\mu\left(\widetilde{v}_{11}-\widetilde{v}_{01}+2 \widetilde{\delta}_{a}\right)\right]
$$

for natives and

$$
\Delta \widetilde{S O C V}=(1-\rho)\left[(1-\mu)\left(\widehat{v}_{10}-\widehat{v}_{00}+2 \widehat{\delta}_{a}\right)+\mu\left(\widetilde{v}_{10}-\widetilde{v}_{00}+2 \widetilde{\delta}_{a}\right)\right]
$$

for immigrants, where $\widehat{\delta}_{a}$ and $\widetilde{\delta}_{a}$ are the average investments in achievement orientation in the two groups. Those average investments increase the social esteem of the achievers and decrease the social esteem of the losers, and hence raise the esteem differential.

The following fact can be established:

Proposition 2 A general equilibrium always exists. Multiple equilibria are possible if $\rho<1$ and $\gamma$ is sufficiently large.

Multiple equilibria are generated by the externality induced by symbolic values: if some agents start investing value on a given endogenous attribute like economic success, the social esteem derived from having that trait increases and induces other agents to 
imitate them. More precisely, an increase of achievement orientation for some children increases the social esteem received by achievers as compared to losers; this strengthens the incentive for other children to exert effort, hence their probability to succeed increases. Anticipating that, their parents have an incentive to raise the achievement orientation of their children, i.e. a bandwagon effect of increasing achievement orientation sets in. In order for this cumulative causation to occur, an increase of achievement orientation must effectively increase the esteem received by achievers relative to that received by losers, $\operatorname{socv}_{1 n}-\operatorname{socv}_{0 n}$. This is only possible if achievement is observable $(\rho<1)$. If achievement is private information, all natives get the same social esteem, independently of their achievement, all immigrants get the same social esteem, independently of their achievement, and social esteem has no behavioral effect. In order for that cumulative causation to generate multiple equilibria, utility must respond strongly enough to changes in social esteem. If a low-achievement-orientation, low-effort economy is a stable equilibrium, a high-achievement-orientation, high-effort economy can also be a stable equilibrium only if the gain of social esteem of achievers in the latter case compensates in utility terms the associated higher effort cost and lower income gain. This requires $\gamma$ to be sufficiently large. ${ }^{9}$

Multiple equilibria are interesting because they reveal the possibility of a drastic effect from improved schooling. In case of multiple stable equilibria, a low-achievementorientation, low-effort equilibrium coexists with a high-achievement-orientation, higheffort equilibrium. Then, a small schooling reform that marginally increases children's abilities $(\pi, \theta)$ may eliminate a stable equilibrium with low achievement orientation, and therefore low social esteem to achievers. Starting from such an equilibrium, the economy will move to a high-achievement equilibrium, where achievers obtain a high level of social esteem. In this case, output grows and the skill wage differential $w_{H}-w_{L}$ decreases because of the increase in the fraction of achievers.

\subsection{Predictions for nationalism}

While natives and immigrants could have similar incentives to shape values about achievement, they have diametrically opposed incentives with respect to nationalism. If the two ethnic groups are otherwise identical, two individuals that only differ with respect to their nationality optimally choose opposite levels of $\delta_{n}$. Those choices determine the diffidence that they experience when they interact. Investments in nationalism may thus be seen

\footnotetext{
${ }^{9} \mathrm{~A}$ similar logic explains the existence of ghetto cultures, where social esteem is obtained in some groups not from achieving in terms of personal income but from achieving in other dimensions, e.g. sexual prowess; see Anderson (1999).
} 
as proxies for interethnic conflict or inversely related to the quality of social interactions between natives and immigrants. ${ }^{10}$

In the current model, nationalism can be predicted by ability. The following result is stated for natives and an equivalent one holds true for immigrants.

Proposition 3 Increasing $\pi$ gradually moves the optimal strategy from configuration 1 to 2 to 3 to 4 as of Proposition 1. The correlation between natives' nationalism and ability is $\frac{\partial \delta_{n}^{*}}{\partial \pi}>0$ in configurations 1 and $2, \frac{\partial \delta_{n}^{*}}{\partial \pi}=0$ in configuration 3 , and $\frac{\partial \delta_{n}^{*}}{\partial \pi}<0$ in configuration 4 .

The comparative statics of $\pi$ crucially depend on the plausible assumption incorporated in (2) that the marginal cost of instilling values increases with $\left|\delta_{a}\right|+\left|\delta_{n}\right|$; that means that putting more pressure on children to strive for economic success makes it harder to press them also to become ardent nationalists. This effect is also at work if parents want to de-emphasize economic success, which is what happens in configurations 1 and 2 . In those configurations, the ability parameter $\pi$ is very low and parents invest to decrease the value attached to achievement $\left(\delta_{a}^{*}<0\right)$ in order to raise their child's future self-esteem. In that range of abilities, when $\pi$ grows, parents become less certain that their child will be a loser. Then, an increase of $\pi$ leads them to make $\delta_{a}^{*}$ less negative, i.e. they come closer to their group's reference values: parents' socialization effort as expressed by $\left|\delta_{a}^{*}\right|$ decreases. As a consequence, the marginal cost of investing in nationalism becomes lower. This leads parents to increase $\delta_{n}^{*}$.

A further increase of $\pi$ moves the optimal strategy into configuration 3. This region is characterized by a corner solution with respect to achievement orientation, i.e. $\delta_{a}^{*}=0$ : the agent endorses the valuation of achievement given by the reference value system of his nationality. This is the parameter region where nationalism reaches its peak since parents can devote their entire socialization efforts to it: no effort is devoted to affect the achievement orientation of children. This occurs because the parent is very uncertain about the future economic status of her child. Economic uncertainty therefore fuels nationalism. ${ }^{11}$

If $\pi$ crosses some threshold, parents invest in achievement values $\left(\delta_{a}^{*}>0\right)$ and configuration 4 occurs. In this region, the complementarity between socialization and child's effort sets in. An increase in $\pi$ leads parents to invest more value in achievement, which increases effort, which increases the probability to succeed, which makes investing in

\footnotetext{
${ }^{10}$ This is consistent with a line of thougth that goes back to Voltaire and the Frankfurt sociological school and that purports that national pride implies ethnic prejudice. For a recent, more nuanced, assessment, see de Figueiredo and Elkins (2003).

${ }^{11}$ This result corresponds to a common finding in social psychology, see e.g. Mullin and Hogg (1998).
} 
achievement even more appealing. The ensuing increase in the marginal cost of socialization leads parents to decrease their investment in nationalism. An increase in child's ability makes therefore parents substitute nationalism with achievement orientation.

The comparative statics of $\theta$ can be explained along similar lines. In configuration $1, e^{*}=0$ so that $\theta$ does not matter. In configurations 2,3 and 4 the effect from $\theta$ is qualitatively identical to the one from $\pi$.

In the most general case, ability entertains a hump-shaped relationship with nationalistic attitudes. At very low levels of ability - such that $e^{*}=0$ and/or $\delta_{a}^{*}<0$ - nationalism is increasing with ability. At intermediate levels - where individuals' uncertainty about future economic perspectives is largest - nationalism peaks and small changes in ability have no effect on it. At higher levels of ability, nationalism continuously declines with ability.

To the extent that $\pi$ and $\theta$ do not only mirror genetic traits but also capture the exogenous quality of schooling received by children, Proposition 3 generates a novel insight into education policy. Suppose that all families find themselves in the realistic case of configuration 4 . Then, more efficient schooling indirectly increases the labor productivity of the next generation because it strengthens the incentive for parents to tilt their children's character away from ethnic complacency and towards conscientiousness and perseverance. As a consequence, the interpersonal relations between migrants and natives improve. Through the incentives it generates with respect to socialization within families, better schooling not only promotes growth but also reduces xenophobia.

\section{Corroborating evidence}

The theoretical model suggests that ability is an explanatory factor of nationalistic attitude. According to Proposition 3, there is an inverted-U relationship between the two variables: there can exist ability levels that are so low that nationalism increases with ability but as soon as some intermediate ability level is reached, nationalism is predicted to decrease with ability. In what follows, I confront that prediction with evidence from survey data. Three datasets are considered: the German DJI Youth Survey, the "National Identity 2003" module of the International Social Survey Programme (ISSP), and the World Value Survey (WVS). Those three surveys share a question that allows one to recover a respondent's degree of nationalism: "How proud are you of being [COUNTRY NATIONALITY]?". Respondents choose from "Very proud", "Somewhat proud", Not very proud", "Not proud at all". Answers to that question are used to determine the value of the dependent variable in econometric regressions. 
In the theoretical model, the explanatory variable "ability" refers to exogenous cognitive skills that mirror inherited family traits and the quality of kindergarten and early schooling - to the extent that they are beyond the effective control of families. In empirical work, cognitive ability is usually measured by scholastic achievement tests, which, unfortunately, are not part of the datasets that contain the nationalism variable. As an indicator of latent cognitive ability, I use educational attainment which, depending on the dataset, is measured by three to six school degrees. As numerous studies document, educational attainment is strongly positively correlated with scholastic achievement tests. The following empirical exercise consists thus in estimating a reduced-form equation of the theoretical model that predicts nationalism on the basis of educational attainment. Although in this way ability will be measured with error and estimates will not be without some bias, it seems unlikely that conclusions about the shape of the relationship between nationalism and ability be driven by such measurement errors. ${ }^{12}$

\subsection{German youth}

The German DJI Youth Survey is a repeated cross-sectional survey which was carried out in 1992, 1997 and 2003. About 20,000 young adults aged 16-29 were interviewed and the survey was designed to be representative of the total German population in that age range. As it focuses on young people, that survey is especially suitable for testing the proposed theoretical model since reported values are not yet affected by the individuals' experience of adult life. Individual ability, measured by a respondent's highest school degree, is available in three categories: "No degree or secondary general school degree"; "Intermediate school degree"; "High school degree". A small fraction of respondents are still in school; since their educational attainment is not necessarily their definitive one, they are omitted from the analysis. ${ }^{13}$ I also omit respondents who have not the German nationality.

The estimated effect of ability on nationalism is displayed in Table 1. The first two columns report results from a binary logit estimation; nationalism is coded as 1 if the

\footnotetext{
${ }^{12} \mathrm{~A}$ more disturbing problem can arise if nationalism causes educational attainment. To some extent, school degrees are likely to be affected by values instilled by parents. Partly because of difficulties in precisely measuring those values, the empirical literature on school outcomes is of limited help in assessing how severe this problem is. For the empirical exercise in this paper, I assume that the employed measures of educational attainment mainly mirror abilities that are independent of parents' investment in values.

${ }^{13}$ Although the omitted respondents are younger than average, the effect does not seem to create a multicollinearity problem. In the samples used, the coefficient of correlation between low education and age never exceeds in absolute value .13 and the one between high education and age never exceeds .14. As a robustness check, regressions were run only considering individuals who are older than twenty and only considering individuals who are at least twenty-two. In all cases, the results were qualitatively similar to those in Table 1.
} 
respondent is very proud of being German and 0 otherwise. The remaining columns report estimations from an ordered logit model.

TABLE 1: Binary and ordered logit regressions predicting nationalism in DJI data.

\begin{tabular}{|c|c|c|c|c|}
\hline & (1) & $(2)$ & $\left(1^{\prime}\right)$ & $\left(2^{\prime}\right)$ \\
\hline \multirow[t]{2}{*}{ Low education } & $0.359^{* * *}$ & $0.330^{* * *}$ & $0.200^{* * *}$ & $0.238^{* * *}$ \\
\hline & $(0.057)$ & $(0.067)$ & $(0.040)$ & $(0.046)$ \\
\hline \multirow[t]{2}{*}{ High education } & $-0.730^{* * *}$ & $-0.520^{* * *}$ & $-0.734^{* * *}$ & $-0.560^{* * *}$ \\
\hline & $(0.068)$ & $(0.093)$ & $(0.036)$ & $(0.050)$ \\
\hline \multirow[t]{2}{*}{ Age } & $-0.216^{*}$ & $-0.258^{*}$ & $-0.119^{*}$ & -0.097 \\
\hline & $(0.086)$ & $(0.125)$ & $(0.055)$ & $(0.084)$ \\
\hline \multirow[t]{2}{*}{ Age squared } & $0.004^{*}$ & 0.005 & 0.002 & 0.002 \\
\hline & $(0.002)$ & $(0.003)$ & $(0.001)$ & $(0.002)$ \\
\hline \multirow[t]{2}{*}{ Female } & $-0.470^{* * *}$ & $-0.507^{* * *}$ & $-0.419 * * *$ & $-0.437^{* * *}$ \\
\hline & $(0.052)$ & $(0.066)$ & $(0.031)$ & $(0.041)$ \\
\hline \multirow[t]{2}{*}{ Wave 1997} & $0.120^{*}$ & 0.108 & $0.125^{* * *}$ & $0.102^{*}$ \\
\hline & $(0.061)$ & $(0.073)$ & $(0.037)$ & $(0.047)$ \\
\hline \multirow[t]{2}{*}{ Wave 2003} & 0.010 & -0.041 & $0.246^{* * *}$ & $0.210^{* * *}$ \\
\hline & $(0.063)$ & $(0.077)$ & $(0.038)$ & $(0.048)$ \\
\hline \multirow[t]{2}{*}{ Married } & & $0.347^{* * *}$ & & $0.337^{* * *}$ \\
\hline & & $(0.080)$ & & $(0.051)$ \\
\hline \multirow[t]{2}{*}{ Widowed } & & & & -0.620 \\
\hline & & & & $(1.084)$ \\
\hline \multirow[t]{2}{*}{ Divorced } & & -0.107 & & $-0.270^{*}$ \\
\hline & & $(0.228)$ & & $(0.134)$ \\
\hline \multirow[t]{2}{*}{ Seperated } & & 0.155 & & -0.087 \\
\hline & & $(0.332)$ & & $(0.203)$ \\
\hline \multicolumn{5}{|l|}{ Primary income source: } \\
\hline \multirow[t]{2}{*}{ Part-time work } & & -0.058 & & $-0.255^{* * *}$ \\
\hline & & $(0.129)$ & & $(0.075)$ \\
\hline \multirow[t]{2}{*}{ Not working } & & -0.028 & & $-0.169^{* *}$ \\
\hline & & $(0.100)$ & & $(0.062)$ \\
\hline \multirow[t]{2}{*}{ Unemployment Benefits } & & $0.283^{* * *}$ & & -0.079 \\
\hline & & $(0.081)$ & & $(0.057)$ \\
\hline Bayesian Information Criterion & 10,944 & 7,368 & 37,060 & 23,261 \\
\hline Observations & 14,583 & 9,115 & 14,583 & 9,117 \\
\hline
\end{tabular}

The results show that educational attainment has a strongly significant impact on the degree of nationalism of the German youth. Individuals with low education are more nationalistic than individuals with intermediate education while individuals with high education are less nationalistic than individuals with intermediate education. The implied negative causal effect of cognitive ability on nationalism is consistent with the comparative 
statics of the model where optimal strategies are based on parameter constellations that lead to configuration 4, i.e. ability levels are relatively high and families invest something in achievement orientation $\left(\delta_{a}^{*}>0\right)$.

Is nationalism associated with negative attitudes towards immigrants? Table 2 shows that in the DJI Youth Survey this is clearly the case. Nationalism is strongly correlated with a number of proxies of xenophobia derived from various survey questions. All reported correlation coefficients are statistically significant at the $1 \%$ level.

TABLE 2: Correlation coefficients for nationalism and various measures of xenophobia.

\begin{tabular}{|l|c|}
\hline Question & Correlation with nationalism \\
\hline $\begin{array}{l}\text { If jobs become rare, foreigners should be } \\
\text { sent to their home countries }\end{array}$ & 0.33 \\
\hline $\begin{array}{l}\text { Foreigners should have the same rights } \\
\text { as Germans in all domains }\end{array}$ & -0.23 \\
\hline $\begin{array}{l}\text { I support the presence of foreigners } \\
\text { because they enrich own cultural life }\end{array}$ & -0.28 \\
\hline $\begin{array}{l}\text { It would be best if all foreigners leave } \\
\text { Germany }\end{array}$ & 0.30 \\
\hline $\begin{array}{l}\text { It is acceptable: Using violent means to } \\
\text { make it clear to asylum-seekers that they } \\
\text { should return to their home country }\end{array}$ & 0.26 \\
\hline
\end{tabular}

\section{$4.2 \quad$ ISSP}

The "National Identity 2003" module of the International Social Survey Programme (ISSP) covers most OECD countries; it samples about 45,000 adult individuals. An advantage of this data source as compared to the DJI Survey is that educational attainment is more finely coded according to the following six categories: "No education"; "Primary education", "Some secundary education", Secundary education", "Above secundary education", "Tertiary education". Regression results are exhibited in Table 3. Again, the first two columns report results from a binary logit estimation and the two other columns report estimations from an ordered logit model. All regressions include unreported country dummies; standard errors are adjusted for clustering by country of the respondent.

TABLE 3: Binary and ordered logit regressions predicting nationalism in ISSP data. 


\begin{tabular}{|c|c|c|c|c|}
\hline & (1) & $(2)$ & $\left(1^{\prime}\right)$ & $\left(2^{\prime}\right)$ \\
\hline \multirow[t]{2}{*}{ No education } & 0.137 & 0.137 & 0.110 & 0.117 \\
\hline & $(0.153)$ & $(0.150)$ & $(0.143)$ & $(0.143)$ \\
\hline \multirow[t]{2}{*}{ Primary education } & $0.161^{* * *}$ & $0.158^{* * *}$ & $0.147^{* * *}$ & $0.145^{* * *}$ \\
\hline & $(0.040)$ & $(0.040)$ & $(0.039)$ & $(0.038)$ \\
\hline \multirow[t]{2}{*}{ Secundary education } & $-0.179^{* * *}$ & $-0.175^{* * *}$ & $-0.171^{* * *}$ & $-0.171^{* * *}$ \\
\hline & $(0.045)$ & $(0.044)$ & $(0.034)$ & $(0.034)$ \\
\hline \multirow[t]{2}{*}{ Above secundary education } & $-0.271^{* * *}$ & $-0.261^{* * *}$ & $-0.249^{* * *}$ & $-0.241^{* * *}$ \\
\hline & $(0.052)$ & $(0.052)$ & $(0.047)$ & $(0.047)$ \\
\hline \multirow[t]{2}{*}{ Tertiary education } & $-0.590^{* * *}$ & $-0.581^{* * *}$ & $-0.524^{* * *}$ & $-0.524^{* * *}$ \\
\hline & $(0.070)$ & $(0.071)$ & $(0.061)$ & $(0.062)$ \\
\hline \multirow[t]{2}{*}{ Age } & 0.012 & 0.008 & 0.008 & 0.002 \\
\hline & $(0.007)$ & $(0.008)$ & $(0.006)$ & $(0.007)$ \\
\hline \multirow[t]{2}{*}{ Age squared } & 0.000 & 0.000 & 0.000 & 0.000 \\
\hline & $(0.000)$ & $(0.000)$ & $(0.000)$ & $(0.000)$ \\
\hline \multirow[t]{2}{*}{ Female } & -0.002 & 0.012 & 0.026 & 0.044 \\
\hline & $(0.040)$ & $(0.038)$ & $(0.036)$ & $(0.033)$ \\
\hline \multicolumn{5}{|l|}{ Legal status: } \\
\hline \multirow[t]{2}{*}{ Married } & & $0.114^{*}$ & & $0.134^{* * *}$ \\
\hline & & $(0.047)$ & & $(0.040)$ \\
\hline \multirow[t]{2}{*}{ Widowed } & & 0.057 & & 0.070 \\
\hline & & $(0.059)$ & & $(0.056)$ \\
\hline \multirow[t]{2}{*}{ Divorced } & & 0.025 & & -0.007 \\
\hline & & $(0.049)$ & & $(0.042)$ \\
\hline \multirow[t]{2}{*}{ Seperated } & & -0.002 & & -0.020 \\
\hline & & $(0.093)$ & & $(0.101)$ \\
\hline \multicolumn{5}{|l|}{ Primary income source: } \\
\hline \multirow[t]{2}{*}{ Part time work } & & $-0.112^{* *}$ & & $-0.138 * * *$ \\
\hline & & $(0.042)$ & & $(0.041)$ \\
\hline \multirow[t]{2}{*}{ Housewife } & & -0.023 & & -0.030 \\
\hline & & $(0.055)$ & & $(0.057)$ \\
\hline \multirow[t]{2}{*}{ Unemployed } & & 0.030 & & -0.039 \\
\hline & & $(0.071)$ & & $(0.078)$ \\
\hline \multirow[t]{2}{*}{ Student } & & -0.008 & & -0.046 \\
\hline & & $(0.062)$ & & $(0.062)$ \\
\hline \multirow[t]{2}{*}{ Retired } & & $0.110^{*}$ & & 0.084 \\
\hline & & $(0.051)$ & & $(0.047)$ \\
\hline \multirow[t]{2}{*}{ Disabled } & & 0.219 & & 0.150 \\
\hline & & $(0.125)$ & & $(0.117)$ \\
\hline Other & & 0.068 & & 0.050 \\
\hline Bayesian Information Criterion & 49,663 & 49,198 & 76,689 & 75,890 \\
\hline Observations & 41,470 & 41,033 & 41,470 & 41,033 \\
\hline
\end{tabular}

Note: All regressions include country dummies.

The omitted education category is "Some secundary education". For higher educa- 
tional attainments, the results show again a negative relationship between education and nationalism. That negative relationship extends to those with only "Primary education", who are found to be more nationalistic than those with "Some secundary education". However, at even lower attainments ("No education") there is no statistically significant effect of education on nationalism, i.e. the nationalism of individuals with no education seems to be closer to that of individuals with some secundary education than to that of individuals with only primary education. ${ }^{14}$

\subsection{WVS}

The third data source is the World Value Survey in its waves 1989-1993, 1994-1999, 1999-2004 and 2005. The distinctive advantage of this source is that it includes many developing countries where educational attainment is relatively low; the sample has more than 250,000 observations. Five levels of educational attainment are available.

TABLE 4: Binary and ordered logit regressions predicting nationalism in WVS data.

\footnotetext{
${ }^{14}$ In this data source there is a survey question directly related to the relative value assigned to the respondent's country. Individuals were asked whether they agree with the following statement: "Generally speaking, [COUNTRY] is a better country than most other countries". Answers are significantly correlated with the nationalism proxy used in the regressions, with a correlation coefficient of 0.33 .
} 


\begin{tabular}{|c|c|c|c|c|}
\hline & $(1)$ & $(2)$ & $\left(1^{\prime}\right)$ & $\left(2^{\prime}\right)$ \\
\hline \multirow[t]{2}{*}{ No education } & -0.054 & -0.044 & -0.061 & -0.048 \\
\hline & $(0.06)$ & $(0.06)$ & $(0.06)$ & $(0.07)$ \\
\hline \multirow[t]{2}{*}{ Primary education } & $0.096^{* *}$ & $0.089^{* *}$ & $0.099^{* *}$ & $0.095^{* *}$ \\
\hline & $(0.03)$ & $(0.03)$ & $(0.03)$ & $(0.03)$ \\
\hline \multirow[t]{2}{*}{ Secundary education } & $-0.118^{* * *}$ & $-0.125^{* * *}$ & $-0.122^{* * *}$ & $-0.127^{* * *}$ \\
\hline & $(0.02)$ & $(0.02)$ & $(0.02)$ & $(0.02)$ \\
\hline \multirow[t]{2}{*}{ Tertiary education } & $-0.263^{* * *}$ & $-0.254^{* * *}$ & $-0.261^{* * *}$ & $-0.259^{* * *}$ \\
\hline & $(0.05)$ & $(0.05)$ & $(0.04)$ & $(0.04)$ \\
\hline \multirow[t]{2}{*}{ Female } & $-0.048^{*}$ & $-0.058 * *$ & -0.018 & -0.025 \\
\hline & $(0.02)$ & $(0.02)$ & $(0.02)$ & $(0.02)$ \\
\hline \multirow[t]{2}{*}{ Age } & -0.004 & $-0.008^{*}$ & -0.004 & $-0.009 * *$ \\
\hline & $(0.00)$ & $(0.00)$ & $(0.00)$ & $(0.00)$ \\
\hline \multirow[t]{2}{*}{ Age squared } & $0.000^{* * *}$ & $0.000^{* * *}$ & $0.000^{* * *}$ & $0.000 * * *$ \\
\hline & $(0.00)$ & $(0.00)$ & $(0.00)$ & $(0.00)$ \\
\hline \multirow[t]{2}{*}{ Married } & & $0.108^{* * *}$ & & $0.127^{* * *}$ \\
\hline & & $(0.03)$ & & $(0.03)$ \\
\hline \multirow[t]{2}{*}{ Divorced } & & $-0.091^{*}$ & & $-0.117^{* *}$ \\
\hline & & $(0.04)$ & & $(0.04)$ \\
\hline \multirow[t]{2}{*}{ Widowed } & & 0.039 & & 0.054 \\
\hline & & $(0.04)$ & & $(0.04)$ \\
\hline \multicolumn{5}{|l|}{ Primary income source: } \\
\hline \multirow[t]{2}{*}{ Part-time work } & & $-0.074^{*}$ & & $-0.082^{* *}$ \\
\hline & & $(0.03)$ & & $(0.03)$ \\
\hline \multirow[t]{2}{*}{ Self-employment } & & $-0.121^{* * *}$ & & $-0.139^{* * *}$ \\
\hline & & $(0.03)$ & & $(0.03)$ \\
\hline \multirow[t]{2}{*}{ Pension } & & $0.112^{* *}$ & & $0.086^{*}$ \\
\hline & & $(0.04)$ & & $(0.04)$ \\
\hline \multirow[t]{2}{*}{ Housewife } & & 0.039 & & 0.026 \\
\hline & & $(0.03)$ & & $(0.03)$ \\
\hline \multirow[t]{2}{*}{ Student } & & -0.020 & & -0.025 \\
\hline & & $(0.03)$ & & $(0.03)$ \\
\hline \multirow[t]{2}{*}{ Unemployment benefits } & & -0.082 & & $-0.124^{* *}$ \\
\hline & & $(0.04)$ & & $(0.04)$ \\
\hline \multirow[t]{2}{*}{ Other } & & -0.043 & & -0.058 \\
\hline & & $(0.05)$ & & $(0.04)$ \\
\hline Bayesian Information Criterion & 288,413 & 273,944 & 437,616 & 418,263 \\
\hline Observations & 249,416 & 236,912 & 249,416 & 236,912 \\
\hline
\end{tabular}

Note: All regressions include country and wave dummies.

The same estimation procedure as for the ISSP data has been employed. Results in Table 4 confirm the same type of results for the WVS data. The declining part of the hump-shaped relationship between ability and nationalism put forward by the theoretical model is clearly detectable in the data, while there is some evidence in support of the 
increasing part of that relationship for low ability levels.

The last wave of the WVS includes information about the nationality of the respondents' parents. According to the theoretical approach proposed in this paper, foreign parents of naturalized individuals are predicted to induce less nationalism because they are unlikely to endorse it in first place - their $\eta$ is lower, i.e. it is more costly for them to instill nationalism. Furthermore, socialization may have taken place behind a veil of ignorance, i.e. before deciding to migrate; this may also imply a lower degree of nationalism for children of foreign parents. Table 5 presents regression results when parent's immigrant status is controlled for. Consistently with expectations, immigrated parents seem to lower their children's degree of nationalism. Interestingly, individuals with no education are found to be significantly less nationalistic than individuals with some secundary education. Among all datasets and specifications examined in this paper, this is the one that delivers the strongest support for the increasing part of the relationship between ability and nationalism put forward by the theoretical model.

TABLE 5: Binary and ordered logit regressions predicting nationalism in WVS data, wave 2005. 


\begin{tabular}{|c|c|c|c|c|}
\hline & $(1)$ & $(2)$ & $\left(1^{\prime}\right)$ & $\left(2^{\prime}\right)$ \\
\hline No education & $\begin{array}{l}-0.204^{* * *} \\
(0.04)\end{array}$ & $\begin{array}{l}-0.181^{* * *} \\
(0.05)\end{array}$ & $\begin{array}{l}-0.227^{* * *} \\
(0.04)\end{array}$ & $\begin{array}{l}-0.204^{* * *} \\
(0.05)\end{array}$ \\
\hline Primary education & $\begin{array}{l}0.063^{*} \\
(0.03)\end{array}$ & $\begin{array}{l}0.074^{*} \\
(0.03)\end{array}$ & $\begin{array}{l}0.067^{*} \\
(0.03)\end{array}$ & $\begin{array}{l}0.082^{* *} \\
(0.03)\end{array}$ \\
\hline Secundary education & $\begin{array}{l}-0.086^{* *} \\
(0.03)\end{array}$ & $\begin{array}{l}-0.082^{* *} \\
(0.03)\end{array}$ & $\begin{array}{l}-0.078^{* *} \\
(0.03)\end{array}$ & $\begin{array}{l}-0.075^{* *} \\
(0.03)\end{array}$ \\
\hline Tertiary education & $\begin{array}{l}-0.220^{* * *} \\
(0.03)\end{array}$ & $\begin{array}{l}-0.218^{* * *} \\
(0.03)\end{array}$ & $\begin{array}{l}-0.226^{* * *} \\
(0.03)\end{array}$ & $\begin{array}{l}-0.227^{* * * *} \\
(0.03)\end{array}$ \\
\hline Female & $\begin{array}{l}-0.086^{* * *} \\
(0.02)\end{array}$ & $\begin{array}{l}-0.082^{* * *} \\
(0.02)\end{array}$ & $\begin{array}{l}-0.059^{* *} \\
(0.02)\end{array}$ & $\begin{array}{l}-0.054^{* *} \\
(0.02)\end{array}$ \\
\hline Age & $\begin{array}{l}-0.003 \\
(0.00)\end{array}$ & $\begin{array}{l}-0.003 \\
(0.00)\end{array}$ & $\begin{array}{l}-0.004 \\
(0.00)\end{array}$ & $\begin{array}{l}-0.006 \\
(0.00)\end{array}$ \\
\hline Age squared & $\begin{array}{l}0.000^{* * * *} \\
(0.00)\end{array}$ & $\begin{array}{l}0.000^{* *} \\
(0.00)\end{array}$ & $\begin{array}{l}0.000^{* * *} \\
(0.00)\end{array}$ & $\begin{array}{l}0.000^{* * *} \\
(0.00)\end{array}$ \\
\hline One Parent Immigrant & $\begin{array}{l}-0.196^{* * *} \\
(0.06)\end{array}$ & $\begin{array}{l}-0.187^{* *} \\
(0.06)\end{array}$ & $\begin{array}{l}-0.183^{* *} \\
(0.06)\end{array}$ & $\begin{array}{l}-0.175^{* *} \\
(0.06)\end{array}$ \\
\hline Both Parents Immigrants & $\begin{array}{l}-0.205^{* * *} \\
(0.05)\end{array}$ & $\begin{array}{c}-0.094 \\
(0.05)\end{array}$ & $\begin{array}{l}-0.192^{* * *} \\
(0.05)\end{array}$ & $\begin{array}{l}-0.097^{*} \\
(0.05)\end{array}$ \\
\hline Married & & $\begin{array}{l}0.101^{* * *} \\
(0.03)\end{array}$ & & $\begin{array}{l}0.121^{* * * *} \\
(0.03)\end{array}$ \\
\hline Divorced & & $\begin{array}{l}-0.097 \\
(0.05)\end{array}$ & & $\begin{array}{l}-0.123^{*} \\
(0.05)\end{array}$ \\
\hline Widowed & & $\begin{array}{l}0.037 \\
(0.05)\end{array}$ & & $\begin{array}{l}0.050 \\
(0.05)\end{array}$ \\
\hline \multicolumn{5}{|l|}{ Primary income source: } \\
\hline Part-time work & & $\begin{array}{l}-0.071 \\
(0.04)\end{array}$ & & $\begin{array}{l}-0.064 \\
(0.04)\end{array}$ \\
\hline Self-employment & & $\begin{array}{l}-0.089^{*} \\
(0.04)\end{array}$ & & $\begin{array}{l}-0.104^{* *} \\
(0.03)\end{array}$ \\
\hline Pension & & $\begin{array}{l}0.075 \\
(0.04)\end{array}$ & & $\begin{array}{l}0.037 \\
(0.04)\end{array}$ \\
\hline Housewife & & $\begin{array}{l}0.017 \\
(0.04)\end{array}$ & & $\begin{array}{l}-0.003 \\
(0.04)\end{array}$ \\
\hline Student & & $\begin{array}{l}0.069 \\
(0.04)\end{array}$ & & $\begin{array}{l}0.063 \\
(0.04)\end{array}$ \\
\hline Unemployment benefits & & $\begin{array}{l}-0.081^{*} \\
(0.04)\end{array}$ & & $\begin{array}{l}-0.108^{* *} \\
(0.04)\end{array}$ \\
\hline Other & & $\begin{array}{l}-0.044 \\
(0.07) \\
\end{array}$ & & $\begin{array}{r}-0.080 \\
(0.06) \\
\end{array}$ \\
\hline Bayesian Information Criterion & 61,509 & 59,043 & 87,559 & 84,618 \\
\hline Observations & 53,592 & 51,483 & 53,592 & 51,483 \\
\hline
\end{tabular}

Note: All regressions include country dummies. 


\section{Conclusion}

Interpersonal relations are embedded in the judgements associated with the social categories that individuals perceive in their fellow human beings. The nature of those judgments can be explained by a theory of symbolic values where agents, e.g. parents, rationally shape individual value systems under some constraints. Using that theoretical framework, I have developed a simple model of relations between natives and immigrants where value of own nationality and disvalue of different ethnicity are endogenously determined. In that model, the formation of value associated with the inherited ethnic trait interacts with the transmission of value attached to an endogenous achievement trait. Values generate economic incentives and are affected by them. Individuals who are less likely to achieve are predicted to invest more value on nationalism and to have hostile relations with immigrants. Multiple equilibria are possible and more effective schooling may eliminate equilibria with xenophobia. Econometric findings from three large surveys corroborate the predictions derived from the theoretical model about the relationship between ability and nationalism.

From a policy perspective, the model in this paper suggests a complementarity between school quality and the integration of immigrants. Between the two extremes of assimilation and ghettoization there exists a whole spectrum of possible relations between natives and immigrants. Integration is a two-sided process. A prerequisite of it is some mutual respect of the identity of the other group. Without mutual esteem, spatial and social segregation are likely to persist. The model in this paper suggests that the development of children's cognitive abilities through better schools has a positive impact on mutual respect and contributes to reduce interethnic conflict. The argument does not rely upon a Victorian view of schools as intruments to improve character, but on the self-interest of agents who socialize their children. The novel idea put forward by the model is that investing resources to increase the cognitive ability of low-ability natives may improve the integration of immigrants in society. Such an investment is predicted to induce parents of children with relatively low cognitive ability to increase their noncognitive abilities by enhancing their achievement orientation, at the same time avoiding to boost their self-esteem through feelings of national or racial superiority. 


\section{APPENDIX}

Proof of Proposition 1: Since parents' and children's interests are perfectly aligned and their information sets are identical, an agent's optimal strategy simply is to maximize (5) with respect to the three control variables $e, \delta_{n}$ and $\delta_{a}$. To begin with, notice that the optimal strategy entails $\delta_{n}^{*} \geq 0$ for a domestic citizen $\left(\delta_{n}^{*} \leq 0\right.$ for an immigrant). Suppose by way of contradiction that the optimal socialization of a domestic citizen entails $\delta_{n}^{*}<0$. Starting from such a situation, a marginal increase in nationalism affects expected utility as follows

$$
\frac{\partial E[U]}{\partial \delta_{n}}=\beta-\frac{\delta_{n}^{*}}{\eta}+\frac{\left|\delta_{a}^{*}\right|-\delta_{n}^{*}}{\sigma}>0,
$$

which contradicts the assertion that $\delta_{n}^{*}<0$.

The four mutually exclusive possible solutions are as follows.

Configuration 1: $\delta_{n}^{*}>0, \delta_{a}^{*}<0, e^{*}=0$.

The FOCs are in this case:

$$
\begin{gathered}
\frac{\partial E[U]}{\partial \delta_{a}}=(2 \pi-1) \beta-\frac{\delta_{a}^{*}}{\alpha}+\frac{\delta_{n}^{*}-\delta_{a}^{*}}{\sigma}=0, \\
\frac{\partial E[U]}{\partial \delta_{n}}=\beta-\frac{\delta_{n}^{*}}{\eta}-\frac{\delta_{n}^{*}-\delta_{a}^{*}}{\sigma}=0,
\end{gathered}
$$

while the corner solution $e^{*}=0$ requires

$$
\left(w_{H}-w_{L}\right)+\beta\left(\widehat{v}_{11}-\widehat{v}_{01}+2 \delta_{a}^{*}\right)+\gamma\left(\operatorname{socv}_{11}-\operatorname{socv}_{01}\right) \leq 0 .
$$

Solving for the FOCs yields:

$$
\begin{gathered}
\delta_{a}^{*}=-\frac{\alpha \beta[(1-2 \pi) \sigma-2 \pi \eta]}{\alpha+\eta+\sigma}, \\
\delta_{n}^{*}=\frac{\beta \eta(\sigma+2 \alpha \pi)}{\alpha+\eta+\sigma} .
\end{gathered}
$$

Configuration 2: $\delta_{n}^{*}>0, \delta_{a}^{*}<0, e^{*}>0$.

The associated FOCs are

$$
\frac{\partial E[U]}{\partial \delta_{a}}=\left[2\left(\pi+\theta e^{*}\right)-1\right] \beta-\frac{\delta_{a}^{*}}{\alpha}+\frac{\delta_{n}^{*}-\delta_{a}^{*}}{\sigma}=0 .
$$

(8) and (6). Solving the equation system yields

$$
e^{*}=\frac{\theta \omega\left\{\left(\Delta w+\beta\left(\widehat{v}_{11}-\widehat{v}_{01}\right)+\gamma \Delta \widehat{s o c v}\right)(\alpha+\eta+\sigma)+2 \alpha \beta^{2}[\eta-(1-2 \pi)(\eta+\sigma)]\right\}}{\alpha+\eta+\sigma-4 \alpha \beta^{2} \theta^{2} \omega(\eta+\sigma)}
$$




$$
\begin{gathered}
\delta_{a}^{*}=-\frac{\alpha \beta\left\{(1-2 \pi) \sigma-2 \pi \eta-2 \omega \theta^{2}\left[\Delta w+\beta\left(\widehat{v}_{11}-\widehat{v}_{01}\right)+\gamma \Delta \widehat{\text { SOCv }}\right](\eta+\sigma)\right\}}{\alpha+\eta+\sigma-4 \alpha \beta^{2} \theta^{2} \omega(\eta+\sigma)} \\
\delta_{n}^{*}=\frac{\beta \eta\left\{\sigma+2 \alpha \pi+2 \alpha \theta^{2} \omega\left[\Delta w+\beta\left(\widehat{v}_{11}-\widehat{v}_{01}\right)+\gamma \Delta \widehat{\text { SOCv }}-2 \beta^{2} \sigma\right]\right\}}{\alpha+\eta+\sigma-4 \alpha \beta^{2} \theta^{2} \omega(\eta+\sigma)} .
\end{gathered}
$$

Configuration 3: $\delta_{n}^{*}>0, \delta_{a}^{*}=0, e^{*}>0$.

The FOCs are (8) and (6). The corner solution $\delta_{a}^{*}=0$ requires

$$
\left[2\left(\pi+\theta e^{*}\right)-1\right] \beta-\frac{\delta_{n}^{*}}{\sigma} \leq 0
$$

and

$$
\left[2\left(\pi+\theta e^{*}\right)-1\right] \beta+\frac{\delta_{n}^{*}}{\sigma} \geq 0 .
$$

The optimal strategy has (6) and

$$
\delta_{n}^{*}=\frac{\beta \eta \sigma}{\eta+\sigma} .
$$

Configuration 4: $\delta_{n}^{*}>0, \delta_{a}^{*}>0, e^{*}>0$.

The FOCs are

$$
\begin{gathered}
\frac{\partial E[U]}{\partial \delta_{a}}=\left[2\left(\pi+\theta e^{*}\right)-1\right] \beta-\frac{\delta_{a}^{*}}{\alpha}-\frac{\delta_{n}^{*}+\delta_{a}^{*}}{\sigma}=0, \\
\frac{\partial E[U]}{\partial \delta_{n}}=\beta-\frac{\delta_{n}^{*}}{\eta}-\frac{\delta_{n}^{*}+\delta_{a}^{*}}{\sigma}=0,
\end{gathered}
$$

and (6). Solving the equation system yields

$$
\begin{gathered}
e^{*}=\frac{\theta \omega\left\{\left(\Delta w+\beta\left(\widehat{v}_{11}-\widehat{v}_{01}\right)+\gamma \Delta \widehat{\operatorname{socv}}\right)(\alpha+\eta+\sigma)+2 \alpha \beta^{2}[(2 \pi-1)(\eta+\sigma)-\eta]\right\}}{\alpha+\eta+\sigma-4 \alpha \beta^{2} \theta^{2} \omega(\eta+\sigma)} \\
\delta_{a}^{*}=\frac{\alpha \beta\left\{(2 \pi-1)(\eta+\sigma)-\eta+2 \omega \theta^{2}\left[\Delta w+\beta\left(\widehat{v}_{11}-\widehat{v}_{01}\right)+\gamma \Delta \widehat{s o c v}\right](\eta+\sigma)\right\}}{\alpha+\eta+\sigma-4 \alpha \beta^{2} \theta^{2} \omega(\eta+\sigma)} \\
\delta_{n}^{*}=\frac{\beta \eta\left\{\sigma+2 \alpha(1-\pi)-2 \alpha \theta^{2} \omega\left[\Delta w+\beta\left(\widehat{v}_{11}-\widehat{v}_{01}\right)+\gamma \Delta \widehat{\text { OOCv }}+2 \beta^{2} \sigma\right]\right\}}{\alpha+\eta+\sigma-4 \alpha \beta^{2} \theta^{2} \omega(\eta+\sigma)} .
\end{gathered}
$$

Simple algebraic manipulations show that the eight remaining possible configurations can never be optimal. QED 
Proof of Proposition 2: Equilibrium existence follows from standard theorems of existence of Nash equilibrium for nonatomic games, see e.g. Rath (1992). Equilibrium multiplicity can be ruled out for $\gamma=0$, while standard social-multiplier arguments show that for $\gamma$ sufficiently large multiple equilibria arise. QED

Proof of Proposition 3: For later use, define

$$
\Gamma \equiv w_{H}-w_{L}+\beta\left(\widehat{v}_{11}-\widehat{v}_{01}\right)+\gamma\left(\operatorname{socv}_{11}-\operatorname{socv}_{01}\right)
$$

and denote by

$$
\Theta \equiv \frac{\alpha+\eta+\sigma}{4 \alpha \beta^{2} \omega(\eta+\sigma)}
$$

the largest possible value of $\theta^{2}$.

Configuration 1: Parameter restrictions are necessary to guarantee $\delta_{a}^{*}<0$ and $e^{*}=$ 0 . If $\Gamma>0$, the condition for $e^{*}=0$ is necessary and sufficient for the existence of configuration 1 ; it can be written as

$$
\pi \leq \frac{2 \alpha \beta^{2} \sigma-(\alpha+\eta+\sigma) \Gamma}{4 \alpha \beta^{2}(\eta+\sigma)} \equiv \pi_{1} .
$$

This configuration only exists if $\pi_{1}>0$, which is assumed to be the case. By differentiating (9) one obtains $\partial \delta_{n}^{*} / \partial \pi>0$.

Configuration 2: It is easy to check that the parameter restriction that implies $e^{*}>0$ also guarantees $\delta_{n}^{*}>0$. That restriction is

$$
\pi>\pi_{1} .
$$

In order for configuration 2 to exist, parameters must also guarantee $\delta_{a}^{*}<0$. This condition can be written as

$$
\pi<\frac{\sigma-2 \theta^{2} \omega(\eta+\sigma) \Gamma}{2(\eta+\sigma)} \equiv \pi_{2}\left(\theta^{2}\right) .
$$

As it is easily checked, $\pi_{2}\left(\theta^{2}\right)>\pi_{1}$ if $\theta^{2} \in(0, \Theta)$ and $\pi_{2}(\Theta)=\pi_{1}$, which shows that configuration 2 occurs if $\pi_{1}<\pi<\pi_{2}\left(\theta^{2}\right)$. By differentiating (11) one obtains $\partial \delta_{n}^{*} / \partial \pi>0$.

Configuration 3: Parameter restrictions are only required to ensure that $\delta_{a}^{*}=0$. Condition (13) is equivalent to

$$
\pi \geq \pi_{2}\left(\theta^{2}\right)
$$

Condition (12) is equivalent to 


$$
\pi \leq \frac{\sigma+2 \eta-2 \theta^{2} \omega(\eta+\sigma) \Gamma}{2(\eta+\sigma)} \equiv \pi_{3}\left(\theta^{2}\right) .
$$

As it is easily checked, $\pi_{3}\left(\theta^{2}\right)>\pi_{2}\left(\theta^{2}\right)$, which shows that configuration 3 occurs if $\pi_{2}\left(\theta^{2}\right) \leq$ $\pi \leq \pi_{3}\left(\theta^{2}\right)$. By differentiating (14) one obtains $\partial \delta_{n}^{*} / \partial \pi=0$.

Configuration 4: The parameter restriction for $\delta_{a}^{*}>0$ also ensures $e^{*}>0$. Condition $\delta_{a}^{*}>0$ is equivalent to

$$
\pi>\pi_{3}\left(\theta^{2}\right)
$$

The equilibrium condition $\delta_{n}^{*}>0$ requires

$$
\pi<\frac{\sigma+2 \alpha-2 \alpha \theta^{2} \omega \Gamma-4 \alpha \beta^{2} \sigma \theta^{2} \omega}{2} \equiv \pi_{4}\left(\theta^{2}\right) .
$$

As it is easily checked, $\pi_{4}\left(\theta^{2}\right)>\pi_{3}\left(\theta^{2}\right)$ if $\theta^{2} \in(0, \Theta)$ and $\pi_{4}(\Theta)=\pi_{3}(\Theta)$, which shows that configuration 4 occurs if $\pi_{3}(\Theta)<\pi<\pi_{4}\left(\theta^{2}\right)$. By differentiating (17) one obtains $\partial \delta_{n}^{*} / \partial \pi<0$.

\section{QED}




\section{References}

Akerlof, G., 1983, Loyalty Filters, American Economics Review 73, 54-63.

Akerlof, G. and R. Kranton, 2000, Economics and Identity, Quarterly Journal of Economics 115, 715-753.

Anderson, E., 1999, Code of the Streets, Harvard University Press: Harvard.

Bisin, A. and T. Verdier, 1998, On the Cultural Transmission of Preferences for Social Status, Journal of Public Economics 70, 75-97.

Bisin, A. and T. Verdier, 2000, Beyond the Melting Pot: Cultural Transmission, Marriage, and the Evolution of Ethnic and Religious Traits, Quarterly Journal of Economics 115, 955-988.

Bisin, A., Patacchini, E., Verdier, T. and Y. Zenou, 2008, "Bend It Like Beckham": Ethnic Identity and Integration, mimeo.

Card, D., Dustmann, C. and I. Preston, 2009, Immigration, Wages, and Compositional Amenities: Modeling Variation in Attitudes to Immigration, mimeo.

Corneo, G., 2005, Work and Television, European Journal of Political Economy 21, 99113.

Corneo, G. and O. Jeanne, 2009, A Theory of Tolerance, Journal of Public Economics 93, 691-702.

Corneo, G. and O. Jeanne, 2010, Symbolic Values, Occupational Choice, and Economic Development, European Economic Review 54, 237-251.

Cunha, F. and J. Heckman, 2009, The Economics and Psychology of Inequality and Human Development, IZA DP No. 4001.

de Figueiredo, R. and Z. Elkins, 2003, Are Patriots Bigots? An Inquiry into the Vices of In-Group Pride, American Journal of Political Science 47, 171-188.

Della Giusta, M. and N. Hashimzade, 2009, Schooling and Intergenerational Transmission of Values, mimeo.

Fershtman, C. and U. Gneezy, 2001, Discrimination in a Segmented Society: An Experimental Approach, Quarterly Journal of Economics 116, 351-77. 
Fortin, N., 2008, The Gender Wage Gap among Young Adults in the United States, Journal of Economic Resources 43, 884-918.

Gui, B., 2005, From Transactions to Encounters: The Joint Generation of Relational Goods and Conventional Values, in Gui, B. and R. Sugden (Eds.), Economics and Social Interactions, Cambridge University Press: Cambridge.

Mullin, B. and M. Hogg, 1998, Dimensions of Subjective Uncertainty in Social Identification and Minimal Inter-Group Discrimination, British Journal of Social Psychology $37,345-365$.

Rath, K., 1992, A Direct Proof of the Existence of Pure Strategy Equilibria in Games with a Continuum of Players, Economic Theory 3, 427-33.

Roemer, J. and K. Van der Straeten, 2005, Xenophobia and the Size of the Public Sector in France: A Politico-Economic Analysis, Journal of Economics 86, 95-144.

Siedler, T., 2008, Parental Unemployment and Young People's Right-Wing Extremism, mimeo.

Vendrik, M. and C. Schwieren, 2010, Identification, Screening and Stereotyping in Labour Market Discrimination, Journal of Economics 99, 141-171. 


\section{Diskussionsbeiträge des Fachbereichs Wirtschaftswissenschaft der Freien Universität Berlin}

2010

2010/1 BÖNKE, Timm / Sebastian EICHFELDER

Horizontal equity in the German tax-benefit system

Economics

2010/2 BECKER, Sascha / Dieter NAUTZ

Inflation, Price Dispersion and Market Integration through the Lens of a Monetary Search Model

Economics

2010/3 CORNEO, Giacomo / Matthias KEESE / Carsten SCHRÖDER The Effect of Saving Subsidies on Household Saving

Economics

2010/4 BÖNKE, Timm / Carsten SCHRÖDER / Clive WERDT

Compiling a Harmonized Database from Germany's 1978 to 2003

Sample Surveys of Income and Expenditure

Economics

2010/5 CORNEO, Giacomo

Nationalism, Cognitive Ability, and Interpersonal Relations

Economics

2010/6 TERVALA, Juha / Philipp ENGLER

Beggar-Thyself or Beggar-Thy-Neighbour? The Welfare Effects of Monetary Policy Economics

$2010 / 7$

ABBASSI, Puriya / Dieter NAUTZ

Monetary Transmission Right from the Start: The (Dis)Connection Between the Money Market and the ECB's Main Refinancing Rates

Economics

2010/8 GEYER, Johannes / Viktor STEINER

Public pensions, changing employment patterns, and the impact of pension reforms across birth cohorts

Economics

2010/9 STEINER, Viktor

Konsolidierung der Staatsfinanzen

Economics

2010/10 SELL, Sandra / Kerstin LOPATTA / Jochen HUNDSDOERFER

Der Einfluss der Besteuerung auf die Rechtsformwahl

FACTS 